\title{
INTRODUCTION: QUANTITATIVE SCIENCE AND TECHNOLOGY INDICATORS STUDIES IN THE FEDERAL REPUBLIC OF GERMANY
}

\author{
H.-D. DANIEL, R. FISCH \\ Universität Konstanz, Fachgruppe Psychologie, \\ Universitätsstraße 10, D-7750 Konstanz (FRG)
}

(Received March 30, 1990)

Scientometric research in the Federal Republic of Germany is a young and active, but not yet firmly established, multi-disciplinary speciality. To present the state of research in scientometrics in the FRG, we have invited contributions from both 'producers' and 'users' of quantitative science and technology indicators studies.

Two thirds of the papers in this issue on scientometric research in the FRG are concerned with performance evaluation in the German university sector. The remaining papers deal with quantitative indicators for the evaluation of a country's competitive position in research and technology.

An overview of the Federal Government education and science policy towards more competition in the university system is provided in the first paper (by Dieter Fichtner). Transparency of performance being a precondition for competition, a comprehensive scientific methodology is required which enables performance to be assessed in a fairly objective manner.

Karl Alewell, the former vice-president of the Westdeutsche Rektorenkonferenz, outlines a reporting system for universities which should allow comparisons of the performance of universities on the basis of various indicators. A survey of German studies on research performance evaluation shows that a standardized evaluation methodology does not yet exist (see Daniel and Fisch). However, most experts would agree with Giese that comparisons of entire institutions across disciplines are of little or no value. Departments and individual researchers within fields are the appropriate levels of analysis for performance evaluation.

At the departmental level a significant number of studies on research performance evaluation has accumulated in the past fifteen years. Many have focused, however, on a single scientific discipline: for the field of Business Administration \& 
Economics at least 16 different evaluation studies have been carried out (see Rau and Hummel).

The next two papers report findings on methodological questions investigated in the field of Business Administration \& Economics. Backes-Gellner and Sadowski, using three different weighting schemes for various categories of publications andthree alternative quality weightings, were able to show that publication indicators as a means of evaluating departmental research performance are thoroughly reliable and robust. The authors stress the importance of differences in input when comparing output performance of departments. They apply the 'frontier production function analysis' to provide relative efficiency measures for departments.

Baumert, Naumann and Roeder present a study on the institutional stratification of university departments in the field of Business Administration \& Economics. In contrast to the still prevailing normative idea of basic equality between academic institutions in the Federal Republic of Germany the empirical results of their study indicate a stable hierarchy of reputation.

One of the first bibliometric studies in the Federal Republic of Germany was carried out by Thomas Finkenstaedt, the former president of the Deutscher Hochschulverband (which is the professional association of university professors in Germany). In his paper, Finkenstaedt reports on his attempts to apply bibliometric indicators in English Studies, the only subject in the humanities investigated so far.

Hartmann and Neidhardt's paper summarizes the findings of an empirical study on proposal review at the Deutsche Forschungsgemeinschaft. Peers use a wide range of criteria for assessing the quality of proposals. The paper reports higher interreferee agreement than has been presented in past papers. The authors conclude that the fate of a grant proposal is about half determined by the explicit assessment of the proposal and the principal investigator and about half by elements "behind the curtain".

Some of the Wissenschaftsrat's recent activities designed to influence the structural development of German universities, Fachhochschulen and research institutes are described by Block and Krull. The authors point out that there has been a shift in the Wissenschaftsrat's evaluative and advisory activities from input towards output assessment during the last two decades.

Schlie-Roosen describes the strategy implemented by the Bundesministerium für Forschung und Technologie to improve knowledge about the output and the competitiveness of the German R\&D system. Several research projects were commissioned and supported by the BMFT, two of which are included in this issue: firstly, Faust's assessment of patent analysis as a device for early identification of 
technological advances and trends and, secondly, Weingart, Sehringer, and Winterhager's study on the potential of bibliographic co-citation methodology for the evaluation of scientific performance.

A comprehensive study on science and technology indicators for telecommunications R\&D in West Germany was carried out by Grupp. The author employs a network of science and technology indicators to analyze institutional set-up and trends in telecommunications R\&D. Analyses were carried out on the national level as well as for single R\&D actors. The main finding of the study is that the various science and technology indicators supplement each other.

A formula for the measurement of a country's science and technology potential is suggested by Pfetsch. The science and technology potential is measured by a country's manpower and financial resources. According to Pfetsch, science and technology potential of Third World countries has increased over the last 20 years at a higher rate than that of the industrialized world.

The final paper in this issue describes the initiatives of the Stifterverband für die Deutsche Wissenschaft for the promotion of Science of Science. The Stifterverband has encouraged and supported research on science and technology indicators since the early seventies. The initiatives of the Stifterverband have helped to reduce the gap between the Federal Republic of Germany and other countries in the development, testing and implementation of scientometric indicators.

Unquestionably, progress has been made over the past fifteen years in developing a methodology for evaluating research and technology. In their contributions for this issue, both the Bundesministerium, für Bildung und Wissenschaft and the Bundesministerium für Forschung und Technologie express their willingness to support the further development of an evaluation methodology. That might help, as Schlie-Roosen points out, to establish science policy research as an academic discipline and scientometrics as one of its methodologies.

The editors of this collection of papers on scientometrics research in the Federal Republic of Germany wish to express their gratitude to the Stifterverband für die Deutsche Wissenschaft for supporting the effort involved in editing a national issue of Scientometrics. James Fearns checked the English of the manuscripts, and Roland Scherer has carried out most of the work in producing a camera ready form of the manuscript. 